\title{
Pelatihan Speaking Dasar Dan Fungsional Untuk Relawan Muda Dan Pemuda Riau
}

\author{
Agung Prasetyo Wibowo*, Prih Febtiningsih, Pahmi, Ardiya, Wandi Syahfutra, \\ Siti Niah \\ Fakultas Keguruan dan Ilmu Pendidikan, Universitas Muhammadiyah Riau \\ email: agungprasetyo.w@umri.ac.id
}

\begin{abstract}
The basic speaking training community service program which is one of the pillars in Higher Education Institution such as Universitas Muhammadiyah Riau is carried out aimed at providing an overview of the importance of knowledge about English and motivation concerning the mastery of English. This was done to make it easier for trainees to understand how certain expressions and vocabulary can be applied in international activities such as the International Youth Exchange Program, International Internships, Scholarship Interviews and so forth. Based on these objectives, the target to be achieved in this program is to provide knowledge of the participants, to develop the ability to speak English so that they can pass international programs, scholarships and continue their postgraduate degree. To achieve the goals and targets of community service activities, the implementers use lecture, discussion, think pair and share, and problem-based learning methods to be conducted, so that the trainees can easily understand the material provided at the training. The activities carried out and participated by program participants came from various University and Higher Education graduates in Riau Province. The training participants were very enthusiastic in participating in the training. This was evidenced by the large number of participants who were active in the discussion session and enthusiastic in taking the activities.
\end{abstract}

Keywords: Social Community Service, Basic and Functional Speaking, English Training

\begin{abstract}
Abstrak
Program pengabdian masyarakat pelatihan speaking dasar yang merupakan salah satu pilar dari Catur Dharma Perguruan Tinggi di Perguruan Tinggi seperti Universitas Muhammadiyah dilakukan bertujuan untuk memberikan gambaran tentang betapa pentingnya pengetahuan tentang bahasa Inggris dan motivasi dalam kaitan penguasaan bahasa Inggris tersebut. Hal tersebut dilakukan agar memudahkan para peserta program pelatiahn untuk bisa memahami bagaimana ekspresi dan kosa kata tertentu bisa diaplikasikan dalam kegiatan Internasional seperti Program Pertukaran Pemuda Antar Negara, Magang Luar Negeri, Wawancara Beasiswa. Berdasarkan tujuan tersebut, maka target yang ingin dicapai dalam program ini adalah memberikan pengetahuan para peserta agar bisa mengembangkan kemampuan dalam berbicara bahasa inggris sehingga mampu lulus programprogram internasional, beasiswa dan melanjutkan studi S2. Untuk mencapai tujuan dan target dari kegiatan pengabdian kepada masyarakat (PKM) tersebut, maka pelaksana menggunakan metode ceramah, diskusi, think pair and share, dan problem-based learning dilakukan, agar peserta pelatihan dapat mudah memahami materi yang diberikan pada pelatihan tersebut. Kegiatan yang dilaksanakan dan diikuti oleh peserta program berasal dari berbagai lulusan Universitas dan Perguruan Tinggi yang ada di Provinsi Riau. Para peserta pelatihan sangat antusias dalam mengikuti pelatihan tersebut, hal ini dibuktikan dengan banyaknya peserta yang aktif dalam sesi diskusi dan antusias dalam mengerjakan aktifitas kegiatan.
\end{abstract}

Kata kuncis: Pengabdian kepada Masyarakat, Speaking Dasar dan Fungsional, Pelatihan Bahasa Inggris 


\section{PENDAHULUAN}

Relawan Muda Riau merupakan organisasi non-profit dan begerak di bidang sosial kemasyarakatan. Dari namanya Relawan, yang berarti mereka yang melakukan aktivitas sosial didasarkan atas rasa kemanusiaan dan tentunya diperuntukkan semua kalangan tanpa terkecuali. Anggota dari organisasi ini ada yang berasal dari akademisi, wirausaha, insinyur, mahasiswa, pelajar dan profesi lainnya. Tidak itu saja, Relawan Muda Riau juga dipandang perlu karena banyaknya antusiasme masyarakat di Provinsi Riau yang ingin memberikan kontribusi kepada masyarakat yang tinggi dan banyaknya anggota organisasi ini yang ingin mengikuti progam beasiswa bergensi seperti CCIP (Community College International Program) di Amerika Serikat, dimana progam ini adalah program pengembangan dan pengabdian masyarakat tingkat Internasioal, dan beasiswa-beasiswa internasional yang berkaitan dengan sosial komunitas lainnya. Untuk menggaungkan Indonesia di kancah internasional, perlu sekali Oganisasi ini didukung untuk pengembangan potensi diri, terutama dengan adanya pelatihan speaking Bahasa Inggris dasar dan fungsional.

Arifuddin dan Sofwan (2015) menjelaskan bahwa pelatihan speaking dasar dan fungsional bertujuan untuk memberikan pemahaman dasar agar nantinya dalam percakapan sehari-hari tidak keliru dalam menggunakan istilah atau kata-kata tertentu. Oleh karena itu, perlu diadakannya pelatihan bahasa inggris dasar dan fungsional ini agar mereka yang ingin mengikuti kegiatan internasional, masih bingung dalam memulai percakapan dan bagaimana langkah-langkah yang harus dilalui dalam mengikuti seleksi progam internasional atau untuk lanjut studi ke luar negeri bisa dengan jelas mendapatkan titik terang dari mereka yang sudah berpengalaman. Proses Rekrutmen Organisasi Relawan Muda
Riau yang berjalan setiap tahunnya, tentu memiliki anggota yang banyak. Hal ini dikarenakan tingginya minat calon peserta sehingga peserta yang ingin ikut, harus menunggu untuk batch selanjutnya. Adapun penitia pelaksana batch selanjutnya adalah mereka yang sudah menjadi pengurus inti. Perlu digarisbawahi bahwa RMR ini tidak dipungut biaya sepeser pun, murni ini adalah kerja ikhlas dan kerja cerdas.

Adapun dalam proses belajar dan mengajar di dalam Pelatihan Speaking Dasar dan Fungsional, metode ceramah, diskusi, think pair and share, dan problembased solving diadopsi. Menurut Seken dan Artini (2013) variasi dalam kegiatan speaking bisa meningkatkan kemampuan peserta didik (dalam hal ini para anggota relawan muda riau) dalam berbicara bahasa Inggris, trutama dengan metode cooperative seperti think pair and share. Untuk itu, memperhatikan pelatihan dengan menggunakan satu metode yang akan menjadi monoton dan jenuh, maka tim pengajar pelatihan ini menggunakan berbagai macam metode agar nanti nya tujuan yang ingin dicapai bisa terpenuhi.

Saat program persiapan ke luar negeri / dengan skala internasional seperti beasiswa, dibutuhkan sebuah persiapan yang matang, sebab kesiapan dalam menjawab pertanyaan saat wawancara, mengisi aplikasi, akan menentukan apakah peserta gagal atau akan berhasil. Jika melamar beasiswa, biasanya wawancara akan digunakan dengan bahasa Indonesia atau bahasa Inggris, apabila pemberi beasiswa dari pihak sponsor dalam negeri. Namun jika peserta melamar di beasiswa pemerintah luar negeri, sudah pasti sesi tanya-jawab akan menggunakan bahasa Inggris secara keseluruhan.

Wawancara merupakan pertemuan antara dua individu untuk saling bertukar informasi dan ide melalui metode tanya jawab sehingga dapat dihasilkan makna dalam suatu pembahasan tertentu (Esterberg, 2002). Wawancara juga cara untuk mengecek ulang dan pembuktian 
terhadap keterangan yang didapat sebelumnya dan juga merupakan teknik komunikasi secara langsung antara penanya dan yang menjawab. Untuk itu, kemampuan berbicara yang baik tentu akan sangat berpengaruh dalam kegiatan wawancara ini. Pelatihan speaking ini memiliki beberapa metode dalam menyampaikan teori dasar dan fungsional dalam berbicara bahasa Inggris. Adapun maksud dari dasar dan fungsional adalah perlu adanya pondasi atau pemahaman mendasar dalam berbicara sehingga dengan mengetahui akan hal ini, mereka akan diwadahi dengan pengaplikasian secara langsung. Untuk itu, dasar dan fungsional bisa diartikan dengan teori dan praktik.

\section{METODE PENGABDIAN}

Adapun beberapa metode yang dilakukan dalam pengabdian Pelatihan Speaking Dasar dan Fungsional bagi Relawan Muda dan Pemuda Riau, yakni ceramah, diskusi, think-pair-share dan problem-based learning. Ceramah merupakan metode pertama yang dianggap efektif dalam pelatihan ini, hal ini dikarenakan untuk pengenalan teori dan pengetahuan dari Speaking dasar dan fungsional (Ardila, Ridha, dan Jauhari, 2014).

Hasil penelitian sebelumnya juga mengatakan bahwa selain ceramah, penambahan metode diskusi juga akan mempermudah peserta untuk mengembangkan dan menggali ilmu yang baru didapat dengan memberikan beberapa pertanyaan terkai dengan materi. Selanjutnya dalam mempraktekkan ilmu yang sudah didapat, maka peseta melakukan kegiatan yang bernama thinkpair-share. Menurut Usman (2015) metode think-pair-share bisa meningkatkan kemampuan berbicara peserta didik,dalam hal ini dikaitkan dengan peserta pelatihan speaking dasar dan fungsional, yakni para relawan muda Riau. Dan bentuk metode terakhir yang digunakan adalah problem-based learning. Problem-based learning merupakan bentuk kegiatan dimana para peserta diberikan permasalahan untuk dipecahkan secara bersama-sama, bisa dengan teman sebangku, bisa dalam satu kelompok yang terdiri dari 3 atau 4 orang. Menurut Yew dan Goh (2016) bahwa strategi ini bisa meningkatkan hasil belajar siswa dan meningkatkan pengetahuan dalam jangka panjang. Untuk itu, penulis merasa bahwa beberapa strategi tersebut dianggap penting untuk diterapkan dalam pelatihan Speaking Dasar dan Fungsional bagi Relawan Muda Riau.

Adapun proses kegiatan ini diawali dengan simulasi wawancara bahasa inggris, hal ini bertujuan untuk mengetahui kemampuan Bahasa Inggris para pemuda dan relawan muda Riau. Setelah dilakukan proses analisis, barulah kelas dimulai dengan menyesuaikan kemampuan bahasa inggris para peserta. Selama kegiatan berlangsung, para peserta diajak untuk berbicara dengan menggunakan bahasa inggris dalam komunikasi sehari hari, dan diberikan beberapa teori dalam speaking untuk mengurangi ketakutan peserta dalam berbicara bahasa inggris serta beberapa kegiatan yang sudah dijelaskan sebelumnya, yakni, diskusi, think-pairshare dan problem-based learning. Tabel berikut diberikan guna untuk mengetahui kegiatan selama program pengabdian ini.

Tabel 1 Jadwal Kegiatan

\begin{tabular}{|l|l|l|l|}
\hline No & Kegiatan & $\begin{array}{l}\text { Bulan } \\
\text { Pertama }\end{array}$ & $\begin{array}{l}\text { Bulan } \\
\text { Kedua }\end{array}$ \\
\hline 1 & $\begin{array}{l}\text { Lokakarya Teori } \\
\text { Berbicara dalam } \\
\text { Bahasa Inggris }\end{array}$ & & \\
\hline 2 & $\begin{array}{l}\text { Lokakarya Teori } \\
\text { Berbicara dalam } \\
\text { Bahasa Inggris }\end{array}$ & & \\
\hline 3 & $\begin{array}{l}\text { Lokakarya } \\
\text { Penerapan teori } \\
\text { dalam bentuk } \\
\text { praktek }\end{array}$ & & \\
\hline 4 & $\begin{array}{l}\text { Lokakarya } \\
\text { Penerapan teori }\end{array}$ & & \\
\hline
\end{tabular}




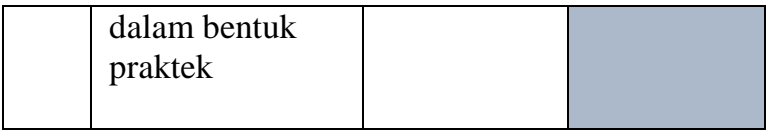

\section{HASIL DAN PEMBAHASAN}

Adapun hasil dari kegiatan pengabdian ini adalah adanya beberapa peserta yang lulus beasiswa dan berhasil melakukan wawancara dalam Bahasa Inggris. Selain itu juga motivasi mereka dalam berbicara bahasa inggris juga meningkat dan mendapat respon positif dari founder RMR serta meningkatnya peserta RMR setiap batch nya. Merujuk dari tingginya minat masyarakat kota Pekanbaru, khususnya para lulusan S1 yang ingin melanjutkan studi ke jenjang lebih tinggi.

Adapun hasil yang sudah dipaparkan di bagian sebelumnya menunjukkan bahwa kegiatan pengabdian masyarakat ini mendapatkan respon yang sangat positif baik dari pihak RMR, maupun masyarakat, dilihat dari tingginya minat dari masyarakat yang ikut daftar program RMR.

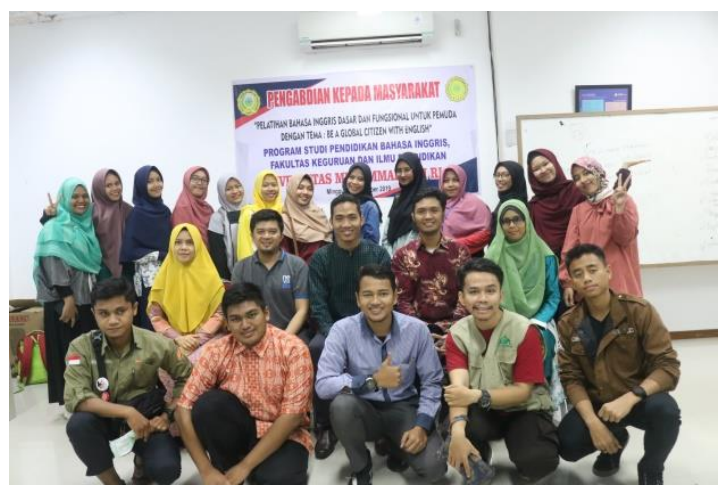

Gambar 1. Suasana pasca kegiatan

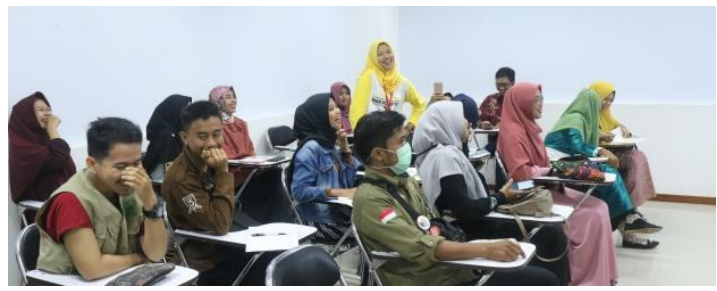

Gambar 2. Saat kegiatan belajar mengajar berlangsung

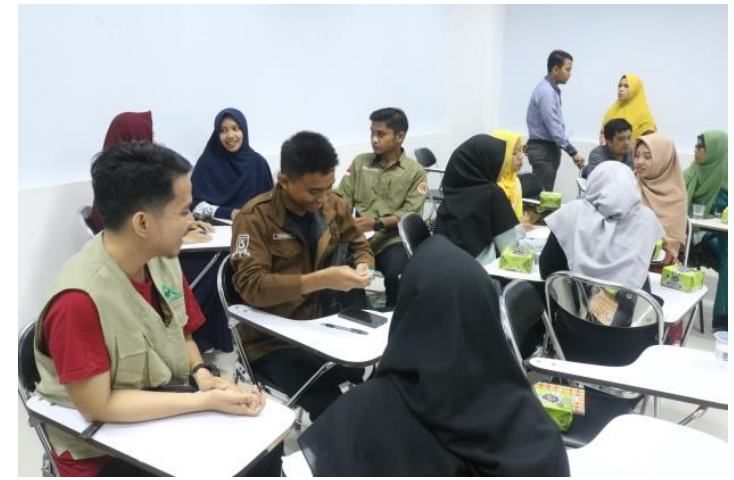

Gambar 3. Kegiatan problem-based learning

Kegiatan ini secara umum berjalan dengan baik, namun perlu adanya dukungan dari pemerintah mengingat tingginya minat masyarakat kota Pekanbaru yang ingin mengikuti seleksi beasiswa untuk melanjutkan sekolah ke jenjang yang lebih tinggi. Adapun kendala mereka adalah dalam kemampuan berbicara bahasa inggris yang masih sangat minim sekali. Beberapa studi menyimpulkan bahwa salah satu kendala dan gagalnya seseorang yang mengikuti seleksi beasiswa ke luar negeri adalah kemampuan berbicara bahasa inggris. Untuk itu, perlu digalakkan khususnya di masyarakat kota pekanbaru untuk meningkatkan kemampuan berbicara bahasa inggris mereka, agar nantinya generasi penerus bangsa dari kota pekanbaru bisa go internasional dan kembali ke daerah untuk mengabdi dan membangun peradaban.

\section{SIMPULAN}

Kemampuan speaking dan persepsi peserta tentang speaking dalam berbahasa Inggris sudah menunjukkan kemajuan. Speaking memang merupakan suatu skill yang tidak mudah, perlu adanya latihan yang serius dan membangun lingkungan dan atmosfir Bahasa Inggris yang memadai. Dengan seringnya latihan berbicara Bahasa Inggris, terutama dengan teman sejawat atau orang di sekitar, hal ini merupakan salah satu faktor yang membantu peserta untuk bisa fasih dalam berbicara Bahasa Inggris. 
Untuk itu, dengan adanya pelatihan ini, para perserta bisa berlatih dan diberikan tata cara menjawab pertanyaan secara detail dengan para ahli yang sudah sering dan terbiasa dalam berbicara Bahasa Inggris, baik itu pengalaman dalam melamar pekerjaan di instansi dalam dan luar negeri, maupun melamar program beasiswa luar negeri.

Antusias peserta sangat terlihat baik saat materi dimulai maupun praktek speaking Bahasa Inggris, Beberapa materi sudah diberikan seperti kumpulankumpulan ekspresi yang sangat berguna dalam menjawab beberapa pertanyaan tertentu, maupun memoles isi jawaban dari pertanyaan. Hal ini diharapkan bisa memperkaya mereka dengan kemampuan berbicara Bahasa Inggris secara formal, kosa kata baru, dan ekspresi-ekspresi yang cocok.

Dengan adanya kegiatan pengabdian kepada Masyarakat ini, tim pelaksana Prodi Pendidikan Bahasa Inggris UMRI bisa menjalankan salah satu kewajibannya dalam Catur Dharma Perguruan Tinggi. Semoga kegiatan ini bisa memberikan manfaat yang meluas bagi masyarakat khususnya di Kota Pekanbaru.

\section{UCAPAN TERIMA KASIH}

Pelaksanaan program Pengabdian kepada Masyarakat ini tentunya tidak terlaksana tanpa bantuan dari berbagai pihak. Oleh karena itu maka penulis mengucapkan terima kasih yang sebesarbesarnya kepada seluruh pihak yang telah membantu baik secara materil maupun moril sehingga kegiatan pengabdian ini dapat terlaksana dengan baik. Adapun ucapan terima kasih tersebut ditujukan kepada Rektor Universitas Muhammadiyah Riau, Ketua LPPM UMRI, Dekan FKIP UMRI, Ketua Program Studi Pendidikan Bahasa Inggris UMRI, Ketua Relawan Muda Riau dan Para Anggota Relawan Muda Riau.

\section{DAFTAR PUSTAKA}

[1] Arifuddin, M., \& Sofwan, A. (2015). Speech Functions and Grammatical Patterns Realization In Conversation In The English Textbook. Lembaran Ilmu Kependidikan, 44(1).

[2] Seken, I. K., \& Artini, L. P. (2013). Pengaruh model pembelajaran kooperatif tipe Think Pair and Share terhadap kemampuan berbicara bahasa Inggris ditinjau dari tingkat kreativitas siswa. Jurnal Pendidikan dan Pembelajaran Bahasa Indonesia, 2.

[3] Ardila, A., Ridha, A., \& Jauhari, A. H. (2014). Efektifitas Metode Diskusi Kelompok dan Metode Ceramah Terhadap Peningkatan Pengetahuan Dan Sikap Remaja Tentang Perilaku Seks Pranikah. Jumantik, 2(1).

[4] Usman, A. H. (2015). Using the think-pair-share strategy to improve students' speaking ability at Stain Ternate. Journal of Education and Practice, 6(10), 37-45.

[5] Yew, E. H., \& Goh, K. (2016). Problem-based learning: An overview of its process and impact on learning. Health Professions Education, 2(2), 75-79 